\title{
A NOVEL ANTIFUNGAL THERAPY
}

\author{
S. SARAN ASWATHAMAN \\ Student, PSG College of Pharmacy, Directly Affiliated to Dr. M.G.R University, \\ Coimbatore, Tamil Nadu, India
}

\begin{abstract}
Current treatment for local and systemic fungal infections, including polyenes, azoles, and currently-approved echinocandins, have significant limitations. Toxicities, drug-drug interactions, low or variable exposure, daily intravenous administration and increasing resistance, are all the issues which will complicate the therapy today in the patients who are already inherently complex and extreme illness.
\end{abstract}

This study is to treat fungal infections with a commensal bacteria in a suitable formulation.

KEYWORDS: Bacteriodetes, Bacteroidesintestinalis, Bacteroidesovatus, Glycan, Cellulose \& Chitin

Received: Oct 19, 2018; Accepted: Nov 09, 2018; Published: Nov 27, 2018; Paper Id.: IJMPSDEC20184

\section{INTRODUCTION}

The cell wall of fungi is made up of chitin, glycans, proteins and sometimes cellulose. In order to stop the fungal growth and its spread ability over the skin and tissues, it is necessary to disrupt the cell wall and kill it.

Bacteriods comes under the phylum BACTERIODETES. They are commensals and animal symbionts which colonizes the GIT of humans. Their main biological function is to degrade high molecular organic matter such as chitin, cellulose, pectin and xylan. They can degrade these organic matter because they possess a large number of genes that encode CAZ enzymes.

Bacteroidetes phylum comprises four classes: Bacteroidia, Flavobacteria, Sphingobacteria, and Cytophagia, representing around 7000 different species. Among them Bacteroidesintestinalis, Bacteroidesovatus are able to degrade chitin, cellulose, pectin, and xylans into monosaccharides.

Since the conventional antifungal therapy like polyenes and azoles has side effects like nausea, head ache, liver damage etc, an antifungal formulation with a fungal cell wall disruptor (commensal bacteria) will be a good alternative.

\section{OBJECTIVE}

To treat local fungal infections with a novel antifungal formulation containing a commensal bacteria (Bacteroides intestinalis, Bacteroides ovatus).

\section{METHODOLOGY}

\section{Culture}

- $\quad$ Bacteroidesintestinalis DSM 17393 
- $\quad$ Bacteroidesovatus ATCC 8483

\section{Media}

- Nutrient broth

\section{TEST ORGANISMS}

Culture of fungi species

- Epidermophytonfloccosum

- Trichophytonrubrum

- Microsporumgypseum

- Candida albicans

The above mentioned fungal species are the common causative agents for local fungal infections such as candidacies, ring worm infestations, tine a infestations, athletes' foot, jock itch etc.

\section{PROCEDURE}

- A nutrient broth is prepared and poured into 4 test tubes.

- The test tubes are marked as A,B, C \&D.

- Each test tube is inoculated with previously standardized cultures of above mentioned fungal species namely,

- Epidermophytonfloccosum- A

- $\quad$ Trichophytonrubrum- B

- Microsporumgypseum- C

- Candida albicans- D

- After inoculation, the test tubes are incubated for 3 hours in 25 degree $\mathrm{C}$.

- Remove the incubated test tubes after 3 hours and inoculate them with previously standardized cultures of,

- $\quad$ Bacteroides intestinalis DSM 17393

- Bacteroidesovatus ATCC 8483

- The bacterial cultures are standardized with 0.5 McFarland standard.

- A positive and a negative control is kept.

- $\quad$ Now the test tubes are incubated overnight at 30 degree $\mathrm{C}$.

- After overnight incubation, the cultures are serially diluted with saline and spread plate is done.

- Incubate the spread plates for 2 days. The first day keep it at 25 degree $\mathrm{C}$ and on the second day keep it at 35 degree $\mathrm{C}$. 
- The produced colonies are viewed under a microscope and the nature of the colonies are determined.

- If only bacterial colonies are present, it can be inferred that the bacteria worked against the fungal species and it can prove with further studies that this bacteria has the potential of becoming an antifungal therapy for local fungal infections.

\section{RESULTS}

The fungal colonies are absent due to the degradation of their cell wall and cell death.

\section{CONCLUSION}

Bacteroidesintestinalis, Bacteroidesovatus can be given as an Anti- Fungal therapy for local fungal infections in a suitable formulation.

\section{REFERENCES}

1. https://www.ncbi.nlm.nih.gov/pmc/articles/PMC5187364/

2. https://www.ncbi.nlm.nih.gov/pmc/articles/PMC3129010/

3. https://www.ncbi.nlm.nih.gov/pmc/articles/PMC5167729/

4. https://bmcmicrobiol.biomedcentral.com/articles/10.1186/1471-2180-9-123

5. https://www.ncbi.nlm.nih.gov/pubmed/16375670

6. https://www.ncbi.nlm.nih.gov/pubmed/21612563

7. https://www.ncbi.nlm.nih.gov/pubmed/23107866

8. https://en.wikipedia.org/wiki/Microsporum_gypseum

9. https://en.wikipedia.org/wiki/Trichophyton_rubrum

10. https://en.wikipedia.org/wiki/Epidermophyton_floccosum 
